\title{
Nutrição e outros aspectos relevantes para a saúde óssea na adolescência
}

\author{
Amina Chain, ${ }^{1,2}$ Maria Eduarda L. D. Melo, ${ }^{3}$ Marise Crivelli, ${ }^{4,5}$ Paula Normando, ${ }^{1}$ Flávia F. Bezerra ${ }^{1 *}$
}

\begin{abstract}
Resumo
A maior fragilidade e o consequente aumento do risco de fraturas que caracterizam a osteoporose são derivados dos processos de perda de massa óssea e deterioração microestrutural ao longo do tempo. Esses processos têm origem complexa e multifatorial, com reconhecida influência predominante de fatores genéticos. Em função de que os tratamentos disponíveis não restauram significativamente o osso já perdido, existe um crescente interesse na prevenção da doença. Garantir condições favoráveis para o ritmo adequado de aquisição óssea na adolescência contribui para o alcance de um pico ótimo de massa óssea no início da vida adulta que, por sua vez, vem sendo considerado o principal método de prevenção da osteoporose. Alguns dos aspectos relevantes para a aquisição óssea do adolescente são tratados nessa revisão. Nutrição, atividade física e condições fisiológicas associadas à adolescência com potencial impacto sobre a taxa de acúmulo ósseo nesse período são abordadas. A potencial influência da composição corporal é também discutida.
\end{abstract}

Descritores: Densidade óssea; Nutrição do adolescente; Composição corporal; Osteoporose.

\section{Abstract \\ Nutrition and other relevant aspects for bone he- alth in adolescence}

The increase in bone fragility and susceptibility to fracture that characterize osteoporosis are derived from the processes of bone loss and micro architectural deterioration over time. These processes have complex and multifactorial origin with recognized predominant influence of genetic factors. Considering that available treatments do not significantly restore bone already lost, there is a growing interest in preventing the disease. Ensuring conditions that favor an adequate bone mass acquisition in adolescence contributes to the achievement of an optimal peak bone mass in early adulthood, which has been considered the primary method of preventing osteoporosis later in life. Some of the relevant aspects for adolescent bone acquisition are considered in this review. Nutrition, physical activity and physiological conditions associated with adolescence with potential impact on bone accumulation rate in this period are addressed. The potential influence of body composition is also discussed.

Keywords: Bone density; Adolescent nutrition; Body composition; Osteoporosis.
1. Programa de Pós-graduação em Alimentação, Nutrição e Saúde. Instituto de Nutrição. Universidade do Estado do Rio de Janeiro. Rio de Janeiro, RJ, Brasil.

2. Seção de Saúde e Qualidade de Vida. Instituto de Pesquisa da Capacitação Física do Exército. Rio de Janeiro, RJ, Brasil.

3. Unidade Técnica de Alimentação, Nutrição e Câncer. Coordenação de Prevenção e Vigilância. Instituto Nacional do Câncer. Rio de Janeiro, RJ, Brasil.

4. Departamento de Reumatologia. Hospital Universitário Pedro Ernesto. Rio de janeiro, RJ, Brasil.

5. Setor de Radiologia. Hospital Naval Marcílio Dias. Rio de Janeiro, RJ, Brasil

"Endereço para correspondência:

Instituto de Nutrição, UERJ

Rua São Francisco Xavier, 524, 12 andar

Rio de Janeiro, RJ, Brasil. CEP: 20550-900

E-mail: flavia.fioruci@gmail.com

Revista HUPE, Rio de Janeiro, 2015;14(3):73-81

doi: 10.12957/rhupe.2015.19943

Recebido em 19/03/2015. Aprovado em 08/07/2015.

\section{Resumen}

\section{Nutrición y otros aspectos relevantes para la salud} ósea en la adolescencia

La mayor fragilidad ósea y el consiguiente aumento del riesgo de fracturas que caracterizan la osteoporosis se derivan de los procesos de pérdida de masa ósea y deterioro micro estructural a lo largo del tiempo. Estos procesos tienen origen complejo y multifactorial con reconocida influencia predominante de los factores genéticos. Ya que los tratamientos disponibles no restauran significativamente el hueso ya perdido, hay un creciente interés en la prevención de la enfermedad. Garantizar condiciones que favorezcan el ritmo adecuado de adquisición ósea durante la adolescencia, contribuye a alcanzar un máximo óptimo de masa ósea en la edad adulta temprana, que a su vez ha sido considerado el principal método para prevenir la osteoporosis. Algunos de los aspectos relevantes para la adquisición ósea de los adolescentes son considerados en esta revisión. Nutrición, actividad física y condiciones fisiológicas asociadas a la adolescencia con un potencial impacto sobre la tasa de acumulación ósea en este período son abordadas. También se discute la posible influencia de la composición corporal.

Palabras clave: Densidad ósea; Nutrición del adolescente; Composición corporal; Osteoporosis. 


\section{Artigo de revisão}

\section{Introdução}

O acúmulo de massa óssea na infância e, principalmente, na adolescência determina a massa óssea ao longo da vida adulta. ${ }^{1}$ Estima-se que cerca de $40 \%$ da massa óssea total de um indivíduo adulto seja adquirida em um intervalo de aproximadamente 5 anos, mais especificamente, entre os estágios puberais de Tanner II e IV, que geralmente ocorrem entre 11 e 15 anos em meninos.,2 Ao final da adolescência, espera-se que cerca de $90 \%$ do pico de massa óssea de um indivíduo tenha sido alcançado. ${ }^{3}$ Se por um lado as elevadas taxas de acúmulo de massa óssea observadas durante a adolescência tornam esse período crucial para o desenvolvimento de estratégias de prevenção da osteoporose, há que se considerar que fatores que afetam negativamente o acúmulo de massa óssea neste período potencialmente contribuem para a maior susceptibilidade ao desenvolvimento futuro da doença.

A massa óssea de um indivíduo é resultado de uma complexa interação entre fatores genéticos e ambientais. Acredita-se que a hereditariedade contribua com $60 \%$ a $80 \%$ da variabilidade interindividual do pico de massa óssea alcançado no início da vida adulta. ${ }^{4} \mathrm{O}$ alcance do potencial genético é, no entanto, dependente da escolha de hábitos de vida, em especial os relacionados à prática de atividade física e à alimentação, usualmente estabelecidos na adolescência. ${ }^{5}$ Em meninas, vale destacar também a potencial interferência de outras condições fisiológicas eventualmente associadas à adolescência, como é o caso da gestação e lactação. Essa revisão discute alguns dos principais aspectos/ condições capazes de afetar a aquisição óssea na adolescência, com ênfase no papel da nutrição neste processo.

\section{Aspectos relevantes na avaliação óssea de crianças e adolescentes}

Os ossos estão em constante renovação tecidual (turnover) em um processo que envolve a integração dos mecanismos de mobilização de osso antigo e a formação de osso novo, mediados pela atividade dos osteoclastos e osteoblastos, respectivamente. ${ }^{6} \mathrm{Na}$ infância e na adolescência, o processo de formação óssea predomina sobre o de mobilização, resultando em ganho líquido de massa óssea, além de modificações de tamanho e de formato dos ossos.

A maior velocidade de acúmulo ósseo característica da adolescência é resultado de adaptações fisiológicas que incluem intensas alterações no perfil hormonal, em especial hormônios esteroides sexuais e hormônio do crescimento.? A idade em que essas alterações se manifestam é bastante variável resultando em graus distintos de maturação biológica em adolescentes com idade cronológica semelhantes. Os indicadores mais comumente usados para determinar a maturação biológica em crianças e adolescentes são a maturação sexual e a maturação esquelética (ou idade óssea). A idade óssea é determinada como a média das idades esqueléticas de diversos pequenos ossos da mão e punho esquerdos e, frequentemente, levada em consideração na interpretação de resultados densitométricos de crianças e adolescentes. ${ }^{8}$

A técnica quantitativa mais utilizada na atualidade é a aquisição de imagem óssea por absorciometria por dupla emissão de raios X (DXA). ${ }^{9}$ O curto tempo de varredura e a baixa dose de radiação são considerados vantagens para o uso dessa técnica em crianças e adolescentes. A imagem do DXA é bidimensional e os valores fornecidos consideram o osso em sua integralidade, ou seja, não há diferenciação entre osso cortical e trabecular.São obtidas informações de densidade e de conteúdo mineral ósseo. Em função da maior acurácia em crianças e adolescentes, os principais sítios de aquisição de imagem nesses indivíduos são a coluna lombar (L1 a L4) e corpo inteiro. Cabe ressaltar que é recomendável que a interpretação dos resultados de corpo inteiro seja realizada desconsiderando-se a região da cabeça em função da densidade óssea muito elevada e de sua proporção em relação ao corpo inteiro da criança e/ ou adolescente..$^{10}$

A massa óssea para a idade é o parâmetro utilizado na avaliação de adequação, sendo considerada baixa massa óssea para a idade quando a densidade mineral óssea é inferior a 2,0 desvios-padrão da média da população de referência (escore $Z<-2,0$ ). No entanto, um escore $Z>-2,0$ não exclui a possibilidade de fragilidade esquelética e aumento do risco de fraturas. ${ }^{10} \mathrm{~A}$ aplicação da densitometria na pediatria, apesar de ampla, ainda requer cuidados tanto no uso da técnica quanto na interpretação dos resutados obtidos. Os resultados podem ser influenciados pelo tamanho do osso, distorções da arquitetura esquelética da criança devido a deformidades, fraturas ou mesmo artefatos de movimento. ${ }^{10}$

\section{Fatores que afetam a aquisição óssea na adolescência}

A aquisição de massa óssea durante a adolescência é afetada por uma série de fatores incluindo determinantes endócrinos, fatores ambientais tais como peso corporal, a ingestão de nutrientes, atividade física, além 
de fatores genéticos, ${ }^{11}$ brevemente discutidos a seguir.

\section{Principais fatores genéticos investigados}

Apesar da diversidade de fatores genéticos envolvidos na determinação da massa, além de sua complexa interação com o ambiente, grande parte dos estudos na última década tem investigado a influência isolada de possíveis genes sobre o risco de fraturas e/ou aquisição óssea. Cerca de 120 genes já foram associados ao metabolismo ósseo e respostas ósseas, ${ }^{11,12}$ entre eles, genes que codificam proteínas da matriz óssea, receptores para hormônios calciotrópicos e esteroides, e reguladores locais do metabolismo ósseo, como citocinas e fatores de crescimento. ${ }^{4}$ Ogene do receptor de estrogênio(ER)e, especialmente, o gene do receptor de vitamina D (VDR) têm recebido a maior parte da atenção nos relativamente poucos estudos com enfoque em adolescentes.

O estrogênio, através da interação com os seus receptores nos ossos e em outros tecidos, desempenha um papel importante na regulação do turnover ósseo, no crescimento do esqueleto e na manutenção da massa óssea. ${ }^{12}$ Os principais polimorfismos no gene do ER que têm sido associados a fenótipos relacionados com os ossos são PvuII (rs2234693) e Xbal (rs9340799).

Em adolescentes, a maior parte dos estudos que associam massa óssea e polimorfismos genéticos têm sido realizados com o gene do VDR, receptor que media as ações genômicas da 1,25(OH)2D. ${ }^{4}$ Este receptor é expresso em diversos tecidos, incluindo aqueles que participam mais diretamente da homeostase do cálcio como o epitélio intestinal, os rins, o tecido ósseo, entre outros tecidos, onde parece regular uma variedade de processos incluindo a proliferação e diferenciação celular. ${ }^{13}$ Mais de 240 polimorfismos foram identificados no gene VDR, mas as principais associações com a massa óssea encontram-se em regiões do gene reconhecidas pelas enzimas de restrição BsmI (rs1544410), ApaI (rs7975232), TaqI(rs731236), Cdx-2 (rs11568820) e FokI (rs10735810). ${ }^{4}$ Alguns desses polimorfismos (ex. ApaI, BsmI e TaqI) parecem não alterar a expressão do gene do VDR e a função do VDR, podendo, no entanto, estar associados com alterações fisiológicas devido a um desequilíbrio de ligação com uma outra variação funcional no gene VDR, ou com outros genes intimamente ligados. Os estudos de associação entre polimorfismos no gene do VDR e a massa óssea têm observado resultados conflitantes entre as diferentes populações estudadas.

Influência da nutrição sobre o metabolismo ósseo e a aquisição óssea na adolescência
As necessidades nutricionais durante a adolescência são em geral aumentadas em função da demanda elevada de nutrientes para garantir a taxa de crescimento físico, incluindo o crescimento e desenvolvimento ósseo. No entanto, a adolescência é marcada por mudanças nas preferências alimentares, questionamentos dos padrões familiares, influência dos grupos de amigos, pressões e modificações que, frequentemente, resultam em escolhas alimentares inadequadas. Considera-se, portanto, que se trata de um período de risco nutricional, especialmente sujeito à alta ingestão de lipídios e carboidratos simples e baixa ingestão de micronutrientes essenciais para a saúde óssea. ${ }^{14}$

A matriz orgânica dos ossos é basicamente proteica e grande parte do conteúdo mineral ósseo é composto por cálcio. ${ }^{15}$ Portanto, proteína e cálcio são nutrientes, indiscutivelmente, importantes para a saúde óssea. Além desses, outros micronutrientes, como zinco, cobre, magnésio e as vitaminas A, D e K têm se mostrado limitantes para o metabolismo ósseo ${ }^{16} \mathrm{e}$, consequentemente, para o acúmulo ósseo em momentos críticos. De fato, muitos nutrientes e outros componentes dos alimentos da dieta ocidental têm potencial impacto (positivo ou negativo) sobre a saúde óssea em diferentes níveis de envolvimento, incluindo função estrutural e de regulação do metabolismo ósseo, tal como exemplificado para alguns nutrientes a seguir. Cabe ressaltar que, embora tratados isoladamente de forma a facilitar o entendimento dos mecanismos que fundamentam seu envolvimento com o metabolismo ósseo, há, na prática, grande dificuldade de se isolar fatores nutricionais, devendo o impacto da nutrição sobre a saúde óssea ser avaliado globalmente.

\section{Proteína}

A matriz óssea proteica corresponde de 20\% a 30\% da massa óssea e é constantemente renovada em um processo essencial para a manutenção da estrutura óssea e expansão em períodos de crescimento. Em função de que as ligações cruzadas do colágeno tipo I (que correspondem a $90 \%$ das proteínas ósseas) envolvem modificações pós-translacionais de aminoácidos (ex.: hidroxilação de lisina e prolina), muitos fragmentos de colágeno liberados durante a proteólise não podem ser reutilizados para síntese de novas proteínas de matriz, havendo, assim, necessidade de constante aporte de aminoácidos para tal. ${ }^{17}$ Além disso, a proteína dietética influencia a síntese de IGF1, um importante estimulador da síntese óssea. Ainda assim, há um longo debate na literatura sobre as potenciais influências benéficas 
e prejudiciais da proteína dietética sobre a saúde óssea. É reconhecido que a proteína é um dos principais contribuintes para a produção de ácidos, como resultado da oxidação de aminoácidos sulfurados. A necessidade do tamponamento sanguíneo em resposta ao aumento da carga ácida resulta em desmineralização óssea e aumento da excreção urinária de cálcio. ${ }^{18} \mathrm{O}$ efeito final da proteína dietética sobre a saúde óssea é, no entanto, dependente de uma série de fatores, incluindo a quantidade, a fonte proteica, a ingestão de cálcio, o peso corporal (e modificações no peso em um determinado período) e o balanço ácido/base da dieta. ${ }^{17}$

\section{Cálcio}

Aproximadamente 99\% do cálcio total do organismo está presente nos ossos, onde o é encontrado sob a forma de sais de fosfato, sendo os cristais de hidroxiapatita $\left[\mathrm{Ca}_{10}(\mathrm{OH})_{2}(\mathrm{PO} 4)_{6}\right]$ a forma predominante. Além da função de sustentação do esqueleto, os ossos contribuem para o controle da homeostase de cálcio atuando como uma reserva prontamente disponível para a manutenção da concentração plasmática que, por sua vez, é fundamental para garantir o desempenho das demais funções biológicas do cálcio em nível celular. Durante a rápida expansão da massa óssea na adolescência, especialmente entre os estágios puberais de Tanner III e IV, a taxa de acúmulo diário de cálcio nos ossos atinge seu máximo (entre 290 mg e 360 mg $\mathrm{Ca} / \mathrm{dia}){ }^{16,19}$ Durante esses períodos de desenvolvimento, a ingestão de cálcio parece ser responsável por cerca de $12 \%$ a $15 \%$ da variabilidade na retenção óssea de cálcio. ${ }^{20}$ Com isso, as atuais recomendações de ingestão desse componente na infância ( 4 a 8 anos, 1000 mg/d) e na adolescência (9 a 18 anos, 1300 mg/d) baseiam-se nas necessidades de cálcio para garantir a máxima retenção diária desse mineral nos ossos nesses períodos.2 A elevada eficiência de absorção intestinal ( 38\%) e o somatório das perdas através da urina, fezes e suor também são considerados. As estimativas das necessidades diárias de cálcio são provenientes de estudos de balanço de cálcio e de acompanhamento do ganho de massa óssea de crianças e adolescentes que têm sido realizados em indivíduos habituados a elevada ingestão de cálcio, submetidos ou não a situações de redução da ingestão ou de suplementação. Pouco se sabe sobre o acúmulo de cálcio ósseo em meninos com baixa ingestão desse mineral, tal como, frequentemente, observado em brasileiros. ${ }^{14}$

Vitamina D
A vitamina D influencia a absorção intestinal de cálcio e a mineralização óssea, por esse motivo, é, potencialmente, um fator de destaque capaz de afetar a aquisição óssea durante a adolescência. Sua atuação sobre a absorção intestinal de cálcio é especialmente importante em situações de baixa ingestão de cálcio, quando há predomínio da via transcelular (dependente de calbidina) de absorção nos enterócitos. Independente da origem dietética, (D2 ou D3) ou via síntese cutânea (D3), a vitamina D é eficientemente convertida a $25(\mathrm{OH}) \mathrm{D}$ (principal indicador de estado nutricional) no fígado, etapa inicial para a posterior formação do metabólito ativo 1,25(OH)2D nos rins. ${ }^{21}$ Recentes avanços metodológicos na análise de vitamina $\mathrm{D}$ em alimentos e amostras biológicas permitiram uma ampla investigação do estado de vitamina D em muitas populações. Surpreendentemente, nos últimos anos, um crescente número de estudos tem observado níveis circulantes de $25(\mathrm{OH}) \mathrm{D}$ inadequados em crianças, adolescentes e adultos, mesmo em regiões com alta exposição à radiação UVB ao longo do ano..$^{22,23}$

\section{Magnésio}

Componente estrutural do tecido ósseo que corresponde à cerca de $60 \%$ do magnésio corporal total. Ele influencia diretamente a qualidade óssea via redução dos cristais de hidroxiapatita e, consequente, o aumento de sua resistência. ${ }^{24}$ Além disso, exerce efeitos indiretos no metabolismo ósseo através de seu papel modulatório sobre o metabolismo de ATP e como cofator de mais de 300 proteínas, incluindo enzimas envolvidas no metabolismo de vitamina D. Além disso, o magnésio é liberado dos ossos quando há necessidade de tamponamento dos ácidos produzidos em resposta à dieta. Estudos observando a associação direta do consumo de frutas e vegetais com a saúde óssea, em parte, atribuem a associação à presença de quantidades expressivas de magnésio (e, por vezes, também a vitamina $\mathrm{K}$ ) nesses alimentos. $^{25}$

\section{Vitamina K}

A vitamina K desempenha uma importante função na carboxilação dos resíduos de ácido glutâmico da osteocalcina (principal proteína não-colágena da matriz óssea) e de outras proteínas GLA (como a periostina). A baixa disponibilidade de vitamina K, seja pelo uso crônico de alguns anticoagulantes ou devido à ingestão insuficiente (suas principais fontes são folhosos verde escuros, frutas e óleos vegetais), pode resultar em um percentual elevado de síntese de osteocalcina não-car- 
boxilada com consequente baixa incorporação dessa proteína na matriz óssea e consequente fragilidade óssea. ${ }^{24}$

\section{Vitamina C}

A vitamina $C$ é essencial na hidroxilação dos resíduos de lisina e prolina e, portanto, envolvida na síntese da principal proteína de matriz óssea, o colágeno tipo I. ${ }^{26}$ Embora não seja consenso na literatura, vários estudos já demonstraram que o consumo de alimentos ricos em vitamina $C$, ou a suplementação com esse nutriente, traz um efeito benéfico para a massa óssea em diferentes populações. ${ }^{27}$

\section{Cobre}

O cobre é um elemento-traço envolvido no metabolismo ósseo como co-fator da lisil oxidase, enzima envolvida na formação das ligações cruzadas do colágeno. ${ }^{28}$ O cobre é, portanto, um nutriente muito importante para a manutenção da integridade e elasticidade do osso. Estudos em animais sugerem que a deficiência de cobre provoca redução da resistência do osso e deterioração da qualidade do osso, levando à osteoporose. ${ }^{29}$ No entanto, em humanos, aparentemente a deficiência de cobre não provoca grandes efeitos negativos sobre a massa óssea. ${ }^{28}$ Ainda assim, há estudos que fornecem evidências de papel benéfico da suplementação de cobre sobre o metabolismo e a massa óssea, incluindo aumento da densidade mineral óssea e qualidade do osso em indivíduos saudáveis ou com osteoporose. ${ }^{30}$

\section{O papel da prática de atividade física}

A prática regular de exercício físico é um importante modulador da massa óssea, de forma que contribui tanto para a manutenção quanto para o incremento da massa óssea durante a infância e a adolescência. Acredita-se que a carga mecânica induzida pelo exercício gere respostas específicas ao tecido ósseo causando modificações na força e na massa óssea. Os efeitos osteogênicos da atividade esportiva são específicos para os locais anatômicos nos quais ocorre a força mecânica e dependentes da frequência, duração e intensidade do exercício ${ }^{31}$ A carga mecânica aplicada ao ossogera sinais em nível celular que podem ativar as células ósseas. Os osteócitos funcionam como sensores mecânicos, traduzindo a força mecânica imposta sobre o esqueleto em sinais bioquímicos que regulam o turnover ósseo resultando em aumento da densidade óssea local. A prática regular de exercício físico atua em sinergia com a nutrição (via ingestão adequada de cálcio) para a otimização do acúmulo de massa óssea em meninos pré-púberes e púberes. ${ }^{32}$

\section{Condições fisiológicas associadas- impacto da gestação e lactação em adolecentes}

Os mecanismos de adaptação do metabolismo ósseo em resposta ao aumento dos requerimentos de cálcio durante a adolescência, a gestação e a lactação, isoladamente, são bastante conhecidos e se mostram eficientes. Esses mecanismos, no entanto, podem não ser suficientes para suprir o aumento dos requerimentos de cálcio, até duplicado, quando gestação e lactação são associadas à adolescência. Há na literatura evidências de que a aquisição de massa óssea característica do período da adolescência seja limitada nessas condições. ${ }^{33,34}$

Gestação e lactação são períodos de elevada demanda de cálcio, com perfil hormonal e adaptações fisiológicas características de cada estado que contribuem para manter a homeostase de cálcio materna a favor do crescimento fetal e da produção de leite materno. Ao longo do período gestacional, aproximadamente $25 \mathrm{~g}$ a $30 \mathrm{~g}$ de cálcio são transferidos ao feto, sendo a transferência materno-fetal de cálcio máxima no terceiro trimestre gestacional ( $~ 330 \mathrm{mg} / \mathrm{dia}){ }_{.}^{35}$ De forma similar, a transferência materna de cálcio para a produção do leite durante a lactação é elevada e representa cerca de $300 \mathrm{mg}$ de cálcio por dia em mães que amamentam de forma exclusiva. ${ }^{35}$

As poucas evidências em mães adolescentes sugerem que, na gestação, a retenção de cálcio ósseo não é suficiente para atender a demanda de cálcio fetal e ainda permitir algum acréscimo de massa óssea da adolescente. ${ }^{33}$ Além disso, a lactação provoca perda de massa óssea materna, principalmente de osso trabecular, de elevada magnitude, e essa perda possivelmente não é completamente recuperada após o desmame. ${ }^{34}$ Sabe-se que, na lactação, a mobilização do cálcio ósseo é um dos principais mecanismos de adaptação materna à elevada demanda de cálcio para a produção do leite. ${ }^{35}$ No entanto, em mães adolescentes, perdas ósseas de maior magnitude ao reportado em adultas ${ }^{36}$ têm sido observadas, ${ }^{33,34,37,38}$ especialmente naquelas com baixa ingestão dietética de cálcio (500-895 mg/dia).34,37,38

Em adolescentes, a recuperação da massa óssea após o desmame é controversa. ${ }^{34,37} \mathrm{Em}$ mães adolescentes argentinas com baixa ingestão de cálcio (500-895 mg/dia) observou-se que a recuperação da massa óssea materna foi quase completamente recuperada doze meses após o parto, similar ao reportado em mães adultas. ${ }^{36}$ Por 
Artigo de revisão

outro lado, em mães adolescentes brasileiras com baixa ingestão dietética de cálcio ( $500 \mathrm{mg} /$ dia), foi observado que a perda óssea da lactação não é completamente recuperada após o desmame, uma vez que déficits de $5 \%$ na densidade mineral óssea da região lombar foram ainda evidentes nessas adolescentes seis a doze meses após o desmame. ${ }^{34}$

Em razão da sobreposta demanda de cálcio da gestação e lactação no organismo adolescente, déficits importantes na massa óssea dessa jovem mãe têm sido reportados durante a lactação ${ }^{33,34,38}$ e podem ser ainda evidentes após o desmame ${ }^{34}$, mesmo frente às adaptações fisiológicas que ocorrem na adolescente. No entanto, ainda não se sabe se a gestação e lactação na adolescência afetam negativamente e/ou de forma permanente a aquisição do pico de massa óssea no início da vida adulta.

\section{Influência da gordura corporal sobre a massa óssea de adolescentes}

Em anos recentes, a potencial influência da composição corporal sobre a massa óssea tem sido investigada em diferentes populações. Na literatura, não existem muitos estudos investigando a influência das massas magra e gorda sobre a massa óssea na população pediátrica. Na população adulta, é bem estabelecido que a massa magra exerça uma influência direta sobre a massa óssea, principalmente pelo efeito de carga mecânica sobre os ossos. Por outro lado, o efeito da massa gorda na DMO permanece controverso..$^{39,40}$

Os estudos conduzidos em crianças e adolescentes mostram influência direta da massa magra sobre a massa óssea. ${ }^{41}$ De forma semelhante ao observado em adultos, o efeito da massa gorda sobre a óssea é questionável. Alguns estudos mostram que a massa gorda é um preditor direto da massa óssea, ${ }^{41-45}$ enquanto outros estudos mostram associação inversa entre essas massas em crianças e adolescentes (Tabela 1). ${ }^{46-50}$

A falta de consenso pode ser parcialmente atribuída a diferentes abordagens estatísticas, especialmente a adoção de diferentes variáveis de ajuste, e ao fato de que a associação entre a DMO e massa gorda parece depender do sexo da população estudada. Alguns estudos mostram ausência de associação ou associação inversa entre a massa gorda e a massa óssea em adolescentes do sexo masculino, ${ }^{45-47}$ enquanto que nas adolescentes, a massa gorda associa-se diretamente com a massa óssea. ${ }^{42,44,45}$ No entanto, as associações parecem ser modificadas em função da adoção de diferentes variáveis de ajuste. Estudos recentes têm mostrado que, após o ajuste pela massa corporal total, a associação entre a massa de gorda e parâmetros da massa óssea torna-se inversa em crianças e adolescentes. ${ }^{48-50}$ Por outro lado, tem sido demonstrado na literatura que, quando a massa magra é considerada como variável de ajuste, a massa gorda associa-se diretamente a ela. ${ }^{44,47,50}$ 
Amina Chain • Nutrição e outros aspectos relevantes para a saúde óssea na adolescência

Tabela 1. Estudos avaliando o efeito da massa gorda sobre a massa óssea de adolescentes.

\begin{tabular}{|c|c|c|c|c|c|c|}
\hline Referência & $\begin{array}{l}\text { Grupo } \\
\text { estudado }\end{array}$ & $\mathbf{n}$ & Nacionalidade & $\begin{array}{l}\text { Idade } \\
\text { (anos) }\end{array}$ & Variáveis de ajuste & Principais resultados obtidos \\
\hline $\begin{array}{l}\text { Ackerman e colabora- } \\
\text { dores }^{41}\end{array}$ & $\begin{array}{l}\text { Meninos } \\
\text { Meninas }\end{array}$ & $\begin{array}{l}482 \\
444\end{array}$ & Americanos & 6 a 18 & $\begin{array}{l}\text { Sem variáveis de } \\
\text { ajuste }\end{array}$ & $\begin{array}{l}\text { Meninos e meninas: Associação (+) entre } \\
\text { massa gorda }(\mathrm{kg}) \text { e CMO do corpo inteiro. }\end{array}$ \\
\hline Janicka e colaboradores ${ }^{46}$ & $\begin{array}{l}\text { Meninos } \\
\text { Meninas }\end{array}$ & $\begin{array}{l}150 \\
150\end{array}$ & Americanos & 13 a 21 & Massa magra & $\begin{array}{l}\text { Meninos: Associações (-) entre a massa } \\
\text { gorda (kg) e DMO e CMO da coluna lombar } \\
\text { e fêmur. } \\
\text { Meninas: Associações (-) entre a massa } \\
\text { gorda (kg) e DMO do fêmur. }\end{array}$ \\
\hline El Hage e colaboradores ${ }^{47}$ & $\begin{array}{l}\text { Meninos } \\
\text { Meninas }\end{array}$ & $\begin{array}{l}65 \\
35\end{array}$ & Franceses & 14 a 16 & Massa magra & $\begin{array}{l}\text { Meninos: Associações (-) entre a massa } \\
\text { gorda }(\mathrm{kg}) \text { e DMO e do corpo inteiro e } \\
\text { da coluna lombar Meninas: Associações } \\
(+) \text { entre a massa gorda }(\mathrm{kg}) \text { e DMO do } \\
\text { corpo inteiro. }\end{array}$ \\
\hline Hong e colaboradores ${ }^{48}$ & $\begin{array}{l}\text { Meninos } \\
\text { Meninas }\end{array}$ & $\begin{array}{l}786 \\
618\end{array}$ & Chineses & 13 a 21 & $\begin{array}{l}\text { MCT, idade, es- } \\
\text { tágio de Tanner, } \\
\text { atividade física }\end{array}$ & $\begin{array}{l}\text { Meninos: Associações (-) entre a massa } \\
\text { gorda (\%) e CMO e AO do corpo inteiro, } \\
\text { coluna lombar e fêmur. } \\
\text { Meninas: Associações (-) entre a massa } \\
\text { gorda (\%) e CMO do corpo inteiro, coluna } \\
\text { lombar e fêmur. }\end{array}$ \\
\hline $\begin{array}{l}\text { Campos e colabora- } \\
\text { dores }^{42}\end{array}$ & $\begin{array}{l}\text { Meninos } \\
\text { Meninas }\end{array}$ & $\begin{array}{l}45 \\
80\end{array}$ & Brasileiros & 14 a 18 & $\begin{array}{l}\text { Sem variáveis de } \\
\text { ajuste }\end{array}$ & $\begin{array}{l}\text { Meninos: Associações (-) entre VAT e } \\
\text { DMO do corpo inteiro e coluna lombar. } \\
\text { Associação (+) entre SAT e DMO do fêmur. } \\
\text { Meninas: Associações (-) entre VAT:SAT e } \\
\text { DMO do corpo inteiro, coluna lombar e } \\
\text { fêmur. Associações (+) entre SAT e DMO } \\
\text { do corpo inteiro }\end{array}$ \\
\hline Junior e colaboradores ${ }^{43}$ & $\begin{array}{l}\text { Meninos } \\
\text { Meninas }\end{array}$ & $\begin{array}{l}92 \\
83\end{array}$ & Brasileiros & 6 a 16 & $\begin{array}{l}\text { Sem variáveis de } \\
\text { ajuste }\end{array}$ & $\begin{array}{l}\text { Meninos e meninas: Associação (+) entre } \\
\text { massa gorda de tronco e DMO do corpo } \\
\text { inteiro. Associação (-) entre VAT e DMO } \\
\text { do corpo inteiro. }\end{array}$ \\
\hline Lee e colaboradores ${ }^{49}$ & $\begin{array}{l}\text { Meninos } \\
\text { Meninas }\end{array}$ & $\begin{array}{l}365 \\
345\end{array}$ & Coreanos & 10 a 19 & $\begin{array}{l}\text { Idade, altura, MCT, } \\
\text { vitamina D sérica, } \\
\text { ingestão de cálcio } \\
\text { e menarca (meni- } \\
\text { nas) }\end{array}$ & $\begin{array}{l}\text { Meninos: Associações (-) entre a massa } \\
\text { gorda (\%) e DMO do corpo inteiro, coluna } \\
\text { lombar e fêmur. } \\
\text { Meninas: Associações (-) entre a massa } \\
\text { gorda (\%) e DMO do corpo inteiro e fêmur. }\end{array}$ \\
\hline Kouda e colaboradores ${ }^{44}$ & $\begin{array}{l}\text { Meninos } \\
\text { Meninas }\end{array}$ & $\begin{array}{l}106 \\
129\end{array}$ & Japoneses & 15 a 18 & Massa magra & $\begin{array}{l}\text { Meninos e meninas: Associações (+) entre } \\
\text { o índice de massa gorda (massa gorda/ } \\
\text { altura }^{2} \text { ) e a DMO do fêmur e o CMO do } \\
\text { corpo inteiro. }\end{array}$ \\
\hline Jeon e colaboradores ${ }^{50}$ & $\begin{array}{l}\text { Meninos } \\
\text { Meninas }\end{array}$ & $\begin{array}{l}433 \\
362\end{array}$ & Coreanos & 12 a 18 & $\begin{array}{l}\text { Modelo 1: Idade, } \\
\text { altura, MCT, vi- } \\
\text { tamina D sérica, } \\
\text { ingestão de cál- } \\
\text { cio e menar- } \\
\text { ca (meninas) } \\
\text { Modelo 2: Idade, } \\
\text { altura, massa } \\
\text { magra, vitamina D } \\
\text { sérica, ingestão de } \\
\text { cálcio e menarca } \\
\text { (meninas) }\end{array}$ & $\begin{array}{l}\text { Modelo 1: } \\
\text { Meninos e meninas: Associações (-) entre } \\
\text { a massa gorda (\%) total, tronco e extrem- } \\
\text { idades e a DMO do corpo inteiro, coluna } \\
\text { lombar e fêmur. } \\
\text { Modelo 2: } \\
\text { Meninos: Associação (+) entre a razão } \\
\text { de massa gorda tronco: extremidades e } \\
\text { a DMO total. } \\
\text { Meninas: Ausência de associação }\end{array}$ \\
\hline El Hage $^{45}$ & $\begin{array}{l}\text { Meninos } \\
\text { Meninas }\end{array}$ & $\begin{array}{c}111 \\
91\end{array}$ & Libaneses & 13 a 30 & $\begin{array}{l}\text { Sem variáveis de } \\
\text { ajustes }\end{array}$ & $\begin{array}{l}\text { Meninos: Ausência de associação. } \\
\text { Meninas: Associação (+) entre massa gorda } \\
(\mathrm{kg}) \text { e DMO do fêmur total e colo do fêmur }\end{array}$ \\
\hline
\end{tabular}

$\mathrm{DMO}=$ Densidade mineral óssea. $\mathrm{CMO}=$ Conteúdo mineral ósseo. $\mathrm{MCT}$ = Massa corporal total 


\section{Artigo de revisão}

\section{Referências}

1. Matkovic V, Jelic T, Wardlaw GM, et al. Timing of peak bone mass in Caucasian females and its implication for the prevention of osteoporosis. Inference from a cross-sectional model. J Clin Invest. 1994 Feb;93(2):799-808.

2. Institute of Medicine. Dietary Reference Intakes for calcium and vitamin D. Washington, DC: The National Academies Press 2011

3. Saggese G, Baroncelli GI, Bertelloni, S. Puberty and bone development. Best Pract Res Clin Endocrinol Metab. 2002 Mar;16(1):53-64.

4. Cusack C; Cashman KD. Impact of genetic variation on metabolic response of bone to diet. Proc Nutr Soc. 2003 Nov; 62(4):901-912.

5. Heaney RP. The importance of calcium intake for lifelong skeletal health.Calcif Tissue Int. 2002 Feb;70(2):70-3. Epub 2002 Jan 21. Review. PubMed PMID:11870410.

6. Rizzoli R, Bianchi ML, Garabédian M, et al. Maximizing bone mineral mass gain during growth for the prevention of fractures in the adolescents and the elderly. Bone. 2010 Feb;46(2):294-305.

7. Veldhuis JD, Roemmich JN, Richmond EJ, et al. Endocrine Control of Body Composition in Infancy, Childhood, and Puberty. Endocr Rev. 2005 Feb;26(1):114-146.

8. Rogol AD, Roemmich JN, Clark PA. Growth at Puberty. J Adolesc Healthy. 2002 Dec;31(6 Suppl):192-200.

9. Blake GM, Fogelman I. The clinical role of dual energy X-ray absorptiometry. Eur J Radiol. 2009 Sep;71(3):406-14.

10. Baim S, Binkley N, Bilezikian JP, et al. Official Positions of the International Society for Clinical Densitometry and executive summary of the 2007 ISCD Position Development Conference. J Clin Densitom. 2008 Jan-Mar;11(1):75-91.

11. Kun Z; Greenfield H; Xueqin D, et al. Improvement of bone health in childhood and adolescence. Nutr Res Rev. 2001 Jun;14(1):119-152.

12. Xu XH, Dong SS, Guo Y, et al. Molecular Genetic Studies of Gene Identification for Osteoporosis: The 2009 Update. Endocr Ver. 2010 Aug;31(4):447-505.

13. Whitfield GK, Remus LS, Jurutka PW, et al. Functionally relevant polymorphisms in the human nuclear vitamin $D$ receptor gene. Mol Cell Endocrinol. 2001 May;177(1-2):145-159.

14. Albano RD, Souza SB. Ingestão de energia e nutrientes por adolescentes de uma escola pública. J Pediatr. 2001 Nov; 77(6):512-516.

15. Heaney, RP. Bone Biology in health and disease: a tutorial. In: Modern Nutrition in Health and Disease. 1998:1327-1364.

16. Vatanparast $H$, Baxter-Jones A, Faulkner RA, et al. Positive effects of vegetable and fruit consumption and calcium intake on bone mineral accrual in boys during growth from childhood to adolescence: the University of Saskatchewan Pediatric Bone Mineral Accrual Study. Am J Clin Nutr. 2005 Sep; 82(3):700-706.

17. Heaney RP, Layman DK. Amount and type of protein influences bone health. Am J Clin Nutr 2008;87(suppl):1567S-70S.

18. Spence L, Weaver C. New perspectives on dietary protein and bone health. J Nutr 2003;133(suppl):S850 -1.

19. Bailey DA, Martin AD, McKay HA, et al. Calcium accretion in girls and boys during puberty: a longitudinal analysis. J Bone Miner Res 2000;15(11):2245-2250

20. Hill MK, Braun M, Kern M, et al. Predictors of calcium retention in adolescent boys. J Clin Endocrinol Metabol. 2008;93:4743-4748.

21. Norman AW. From vitamin $D$ to hormone $D$ : fundamentals of the vitamin $D$ endocrine system essential for good health. Am J Clin Nutr 2008;88(suppl):491S-9S.
22. Willis CM, Laing EM, Hall DB, et al. A prospective analysis of plasma 25-hydroxyvitamin D concentrations in white and black prepubertal females in the southeastern United States. Am J Cin Nutr 85:124-30, 2007.

23. Jacobs ET, Alberts DS, Foote JA, et al. Vitamin D insufficiency in southern Arizona. Am J Cin Nutr. 2008; 87:608-13..

24. Bonjour JP, Guéguen L, Palacios C, et al. Minerals and vitamins in bone health: the potential value of dietary enhancement. $\mathrm{Br} J$ Nutr. 2009 Jun;101(11):1581-1596.

25. New S. Intake of fruit and vegetables: implications for bone health. Proc Nutr Soc. 2003;62:889-99.

26. Leveille SG, LaCroix AZ, Koepsell TD, et al. Dietary vitamin C and bone mineral density in postmenopausal women in Washington State, USA. J Epidemiol Community Health.1997 Oct; 51(5):479-485.

27. Hall SL, Greendale GA. The relationship of dietary vitamin C intake to bone mineral density: results from the PEPI study. Calcif Tissue Int. 1998;63:183-9.

28. Nieves, JW. Osteoporosis: the role of micronutrients. Am J Clin Nutr. 2005 May;81(5):1232S-1239S.

29. Medeiros DM, Ilich J, Ireton J, et al. Femurs from rats fed diets deficient in copper or iron have decreased mechanical strength and altered mineral composition. J Trace Elem Exp Med. 1998 Dec;10(3):197-203.

30. Gür A, Colpan L, Nas K, et al. The role of trace minerals in the pathogenesis of postmenopausal osteoporosis and a new effect of calcitonin. J Bone Miner Metab. 2002;20(1):39-43.

31. Vainionpää $A$, Korpelainen $R$, Väänänen $H K$, et al. Effect of impact exercise on bone metabolism. Osteoporos Int. 2009 Oct;20(10):1725-33.

32. Bass SL, Naughton G, Saxon L, et al. Exercise and calcium combined results in a greater osteogenic effect than either factor alone: a blinded randomized placebo-controlled trial in boys. J Bone Miner Res. 2007 Mar;22(3): 458-464.

33. O’Brien KO, Nathanson MS, Mancini J, et al. Calcium absorption is significantly higher in adolescents during pregnancy than in the early postpartum period. Am J Clin Nutr.2003 Dec;78(6):1188-1193.

34. Bezerra FF, Mendonça LM, Lobato EC, et al. Bone mass is recovered from lactation to postweaning in adolescent mother with low calcium intakes. Am J Clin Nutr. 2004 Nov;80(5):1322-1326.

35. Prentice A. Micronutrients and the bone mineral content of the mother, fetus and newborn. J Nutr. 2003 May;133(5 Suppl2):1693S-1699S.

36. Olausson H, Goldberg GR, Laskey MA, et al. Prentice A. Calcium economy in human pregnancy and lactation. Nutr Res Rev. 2012 Jun;25(1):40-67.

37. Malpeli A, Mansur JL, Santiago SD, et al. Changes in bone mineral density of adolescent mothers during 12-month postpartum period. Pub Health Nutr. 2009 Oct;13(10):1552-1527.

38. Diogenes MEL, Bezerra FF, Rezende EP, et al. Effect of calcium plus vitamin D supplementation during pregnancy in Brazilian adolescent mothers: a randomized, placebo-cotrolled trial. Am J Clin Nutr. 2013 Jul;98(1):82-91.

39. Zhao LJ, Liu YJ, Liu PY, et al. Relationship of obesity with osteoporosis. J Clin Endocrinol Metab. 2007;92:1640-1646.

40. Ho-Pham LT, Nguyen DT, Nguyen TV. Association between lean Mass, fat mass, and bone mineral density: A Meta-analysis. J Clin Endocrinol Metab. 2014 Jan; 99(1):30-38.

41. Ackerman A, Thornton JC, Wang J, et al. Sex difference in the effect of puberty on the relationship between fat mass and bone mass in 926 healthy subjects, 6 to 18 years old. Obesity. 
2006 May; 14(5):819-825.

42. Campos RM, Lazaretti-Castro M, Mello MT, et al. Influence of visceral and subcutaneous fat in bone mineral density of obese adolescents. Arq Bras Endocrinol Metabol. 2012 Feb; 56(1):12-18.

43. Júnior IF, Cardoso JR, Christofaro DG, et al. The relationship between visceral fat thickness and bone mineral density in sedentary obese children and adolescents. BMC Pediatr. 2013 Mar;13:37.

44. Kouda K, Fujita Y, Sato Y, et al. Fat mass is positively associated with bone mass in relatively thin adolescents: Data from the Kitakata Kids Health Study. Bone, 2014 Jul;64:298-302.

45. El Hage R. Fat mass index and hip bone mineral density in a group of Lebanese adolescents and young adults. J Med Libian. 2014 Jul-Sep;62(3):137-142.

46. Janicka A, Wren TA, Sanchez MM, et al. Fat mass is not beneficial to bone in adolescents and young adults. J Clin Endo- crinol Metab. 2007 Jan;92(1) 143-147.

47. El Hage RP, Courteix D, Benhamou CL, et al. Relative importance of lean and fat mass on bone mineral density in a group of adolescent girls and boys. Eur J Appl Physiol. 2009 Mar;105(5):759-764.

48. Hong X, Arguelles LM, Liu X, et al. Percent fat mass is inversely associated with bone mass and hip geometry in rural Chinese adolescents. J Bone Miner Res. 2010 Jul; 25(7):1544-1554.

49. Lee K. Regional percent fat and bone mineral density in Korean adolescents: the Fourth Korea National Health and Nutrition Examination Survey (KNHANES IV-3), 2009. Asia Pac J Clin Nutr. 2013;22(1):69-73.

50. Jeon HC, Lee K, Kim J, et al. The Relationship between Body Fat Percent and Bone Mineral Density in Korean Adolescents: The Fifth Korea National Health and Nutrition Examination Survey (KNHANES V-1), 2010. Korean J Fam Med. 2014 Nov;35(6):303-308. 